\title{
Postoperative lung injury and oxidative damage in patients undergoing pulmonary resection
}

\author{
E.A. Williams*, G.J. Quinlan*, P. Goldstraw**, J.W.W. Gothard*, T.W. Evans*
}

Postoperative lung injury and oxidative damage in patients undergoing pulmonary resection. E.A. Williams, G.J. Quinlan, P. Goldstraw, J.W.W. Gothard, T.W. Evans. CERS Journals Ltd 1998.

ABSTRACT: Postpneumonectomy pulmonary oedema (PPO) complicates a significant number of thoracic surgical procedures involving lung resection and in its extreme form is indistinguishable from the acute respiratory distress syndrome. This study investigated the possibility that ischaemia-reperfusion (I-R) injury contributes to PPO via the production of damaging reactive oxygen species.

In a prospective, observational, comparative study, patients undergoing pneumonectomy, lobectomy, or wedge resection or open lung biopsy were investigated for perioperative changes in lung function indicative of lung injury and changes in plasma indices of oxidative damage.

Significant percentage perioperative falls in plasma protein thiol levels $(-17.9 \pm$ $\mathbf{7 . 0 \%}$ for pneumonectomy, $-\mathbf{2 4 . 3} \pm \mathbf{5 . 5 \%}$ for two-lobe lobectomy and $\mathbf{- 1 0 . 2 \pm 2 . 2 \%}$ for one-lobe lobectomy, $\mathbf{p}<\mathbf{0 . 0 5})$ and rises in plasma protein carbonyl levels $(26.2 \pm 10.5 \%$ for pneumonectomy, $p<0.05,9.8 \pm 7.0 \%$ for two-lobe lobectomy and $5.0 \pm 2.7 \%$ for onelobe lobectomy) were identified, but not in patients undergoing biopsy or wedge resection. Plasma myeloperoxidase levels rose in all groups, but not significantly. The carbon monoxide transfer coefficient $(\mathrm{KCO})$ fell significantly in patients undergoing lobectomy $(\mathrm{p}<0.05)$ but not in those undergoing wedge resection, lung biopsy or pneumonectomy.

Changes in markers of oxidative protein damage occurred in patients undergoing lung resection, although the gas transfer coefficient fell significantly only following lobectomy. Oxidative damage occurs during pulmonary resection, although associated effects on gas exchange are seen only after lobectomy.

Eur Respir J 1998; 11: 1028-1034.

Lung injury is a potential complication of lung resection and has been termed postpneumonectomy pulmonary oedema (PPO) $[1,2]$. In its extreme form, PPO represents one cause of the acute respiratory distress syndrome (ARDS) and the less severe acute lung injury (ALI) [3]. PPO complicates $4-7 \%$ of pneumonectomies and $1-7 \%$ of lobectomies, with an associated mortality of 50-100\% [47], and therefore represents a significant operative complication. Predicting patients at risk of developing PPO has proved difficult. Age, the side of lung resection [5], the volume of fluid infused perioperatively $[1,8]$, and preoperative lung function have all been proposed as possible predictive factors, but with little statistical support. The pathophysiology of PPO is uncertain, although the use of fresh frozen plasma, mechanical ventilatory support [9] and the extent of mediastinal lymphatic dissection [10] may be contributory factors.

Ischaemia-reperfusion (I-R) injury may also contribute to PPO, in that operative ischaemia may lead to lung damage, but on reperfusion injury is increased owing to the formation of reactive oxygen species (ROS) [11, 12], possibly secondary to neutrophil recruitment and activation in the lung $[13,14]$. I-R-mediated damage is known to occur following rapid re-expansion of a collapsed lung, after removal of thrombus in massive pulmonary embolus and
Dept of *Anaesthesia and Intensive Care and **Thoracic Surgery, Royal Brompton Hospital, London, UK.

Correspondence: T.W. Evans

Intensive Care Unit

Royal Brompton Hospital

Sydney Street

London SW3 6NP

UK

Fax: 441713518524

Keywords: Free radicals ischaemia reperfusion lung injury

lung resection

oxidative damage

postpneumonectomy

Received: October 21997

Accepted after revision February 51998

Supported by the British Lung Foundation. following lung transplantation. Furthermore, evidence of ROS-mediated oxidative damage has been found in patients with ARDS precipitated by a wide variety of serious medical and surgical conditions $[15,16]$.

The primary aim of this investigation was therefore to seek evidence of oxidative damage and lung injury in patients undergoing routine thoracic surgery involving onelung ventilation. During lobectomy, the relevant lung may be partly or completely collapsed, potentially suffering IR-mediated injury on re-expansion. During pneumonectomy or open lung biopsy, the lung is less frequently manipulated in this fashion. To evaluate the possible connection between evidence of ROS activation, clinically detectable lung injury and the type of surgical resection, patients undergoing pneumonectomy, lobectomy and lesser resections (wedge, segmentectomy or open lung biopsy with a low risk) were investigated.

\section{Methods}

\section{Study subjects}

Patients over 18 yrs of age scheduled to undergo elective thoracic surgery and providing informed consent were 
considered eligible for the investigation, the protocol for which was approved by the Ethics Committee of the Royal Brompton Hospital. For plasma myeloperoxidase assays (MPO), blood samples from 10 normal controls were also analysed. A further group of adult control surgical patients undergoing routine abdominal surgery $(n=5)$ was also included in the study.

\section{Study design}

Surgical procedure and lung function. Following the induction of anaesthesia with propofol $\left(0.1 \mathrm{mg} \cdot \mathrm{kg}^{-1}\right)$, etomidate $\left(0.2 \mathrm{mg} \cdot \mathrm{kg}^{-1}\right)$ and pancuronium $\left(0.15 \mathrm{mg} \cdot \mathrm{kg}^{-1}\right)$, patients were intubated with a single lumen endotracheal tube of appropriate size prior to rigid bronchoscopy. Rebreathing measurements of lung function were then assessed with the patient supine, prior to repositioning for surgery. In patients in whom bronchoscopy had been performed during an earlier procedure, measurements were performed through the appropriate double-lumen tube, ensuring in each case that the corresponding tube was used for all repeated measurements. Anaesthesia was maintained with intravenous propofol and/or alfentanyl, and in most cases with a diamorphine epidural. Blood samples were collected from indwelling catheters at designated time points (see below). During one-lung ventilation, a tidal volume of 10 $\mathrm{mL} \cdot \mathrm{kg}^{-1}$ was used, reduced to $8 \mathrm{~mL} \cdot \mathrm{kg}^{-1}$ if inflation pressures exceeded $35 \mathrm{cmH}_{2} \mathrm{O}$, but frequency was then increased to maintain an equivalent minute volume. Positive end-expiratory pressure (PEEP) was not used during onelung ventilation, the duration of which and the volume of colloid and crystalloid transfused were recorded. After surgery, a further blood sample was collected and duplicate measurements of lung function were repeated.

Markers of oxidative damage and inflammation. Direct measurement of oxidative damage to biological molecules harvested from the lung was not possible, owing to technical problems associated with the operative procedure and patient welfare. Previous clinical studies have used markers of lipid peroxidation to assess oxidative damage but these are often nonspecific. Therefore, oxidative damage to proteins was quantified as an index of ROS formation (loss of plasma thiols and formation of protein carbonyls) [17]; for review see [18]. It was ensured that changes in plasma thiols were not merely due to a fall in thiol-containing molecules (e.g. albumin) by showing in pilot studies that plasma albumin remained constant as a percentage of total protein in five patients undergoing lung resections. Arterial and/or mixed venous blood samples were collected into lithium heparin tubes at specified time points. Aliquots of plasma for thiol measurement were analysed immediately and those for carbonyl measurements stored at $-20^{\circ} \mathrm{C}$ for no longer than 4 weeks before analysis. Ellman's test was modified to determine the protein thiol (sulfydryl) content in plasma [17]. Protein carbonyls were assessed using a modified version of the dinitrophenylhydrazine technique [17]. Results of both thiol and carbonyl assays were expressed as nmol.mg-1 protein, the latter being determined using a commercially available kit (Sigma Chemicals, Poole, UK).
Neutrophil activation indicated by plasma MPO was also measured in plasma samples collected following the induction of anaesthesia (time-point one, TP1), immediately following completion of the operative procedure and transfer of the patient to the high-dependency unit before extubation (TP2) and $24 \mathrm{~h}$ postoperatively (TP3). In the first 12 patients studied, a preoperative sample was collected at the time of admission to hospital during the $24 \mathrm{~h}$ preceding surgery. Plasma protein and thiol levels for these samples were not significantly different to those obtained at TP1 following the induction of anaesthesia (data not shown). An enzyme-linked immunoassay (ELISA) was em-ployed to measure MPO using a commercially available kit (MPO-EIA; Bioxytech SA, France), and concentrations were expressed in $\mathrm{nmol} \cdot \mathrm{mL}^{-1}$ plasma following correction for dilution.

Measurement of lung volumes and diffusing capacity. A bag-in-box rebreathing system adapted by MACNAUGHTON [19, 20] for use in ventilated patients and described in de-tail elsewhere was used to assess perioperative changes in the carbon monoxide transfer coefficient $(K \mathrm{CO})$. Haemoglobin and carboxyhaemoglobin levels were measured sim-ultaneously (270 Co-oximeter; Ciba Corning, Essex, UK) and the results corrected to a haemoglobin level of $14.6 \mathrm{~g} \cdot \mathrm{dL}^{-1}$. End-expiratory volume, functional residual capacity (FRC), the transfer function of the lung for $\mathrm{CO}(T \mathrm{~L}, \mathrm{CO})$ and $K \mathrm{CO}$ were calculated from standard equations. Conditions of measurement were standardized by carrying out all measurements in duplicate, with the patient supine and ventilated with an inspiratory oxygen fraction $\left(F \mathrm{I}, \mathrm{O}_{2}\right)$ of 0.7 corresponding to the test gas composition. The ventilator was flushed for $1 \mathrm{~h}$ with oxygen before use in order to eliminate any interference from volatile anaesthetic gases in the measurement by infrared analysis of carbon monoxide.

Other measurements. Serum albumin, forced expiratory volume in one second (FEV1)/forced vital capacity (FVC) and $\mathrm{O}_{2}$ tension in arterial blood $\left(\mathrm{Pa}_{\mathrm{a}} \mathrm{O}_{2}\right)\left(\mathrm{FI}, \mathrm{O}_{2} 0.21\right)$ were recorded for each patient, together with formal preoperative lung function assessment (where available). The intraoperative fluid balance was noted. Predicted postoperative FEV1 was calculated retrospectively following the definitive operative procedure from knowledge of ventilation-perfusion distribution were formally assessed, or approximated using the formula:

Predicted postoperative $\mathrm{FEV} 1=$ Proportional remaining functional lung volume

Preoperative FEV1

Final staging according to the Tumour Nodes Metastases (TNM) classification was obtained from the postoperative histology records.

\section{Data analysis}

Data are presented throughout as mean \pm SEM, as actual amounts measured and as percentage change. Student's paired t-test was used to assess differences between means for all paired data sets. One-way analysis of variance (ANOVA) was used for comparisons between multiple data sets, followed by Tukey-Kramer multiple comparison 
post-testing where a significant p-value was realized. Graphpad Scientific Software (San Diego, CA, USA) was used throughout. P-values ð0.05 were considered significant.

\section{Results}

\section{Demographic features}

Complete data sets were obtained for eight patients in each group, with the exception of two undergoing pneu- monectomy and one undergoing lobectomy in whom the administration of total intravenous anaesthesia was clinically inappropriate, precluding the measurement of lung function (table 1). There was no significant difference in age, preoperative spirometry, or preoperative $\mathrm{Pa}, \mathrm{O}_{2}$ between groups, but the preoperative serum albumin level was significantly lower for patients undergoing lobectomy than for those requiring biopsy or wedge resection. The duration of one-lung ventilation (and of total anaesthesia) was significantly longer for patients undergoing major resection than for those undergoing a lesser procedure. The first two groups also received a greater intraoperative fluid

Table 1. - Demographic details of patients undergoing pneumonectomy, lobectomy and biopsy or wedge resection

\begin{tabular}{|c|c|c|c|c|c|c|c|c|c|}
\hline $\begin{array}{l}\text { Age } \\
\text { yrs }\end{array}$ & Operation & $\begin{array}{l}\text { Preop } \\
\text { albumin } \\
\mathrm{mg} \cdot \mathrm{mL}^{-1}\end{array}$ & $\begin{array}{l}\text { Length } \\
\text { of stay } \\
\text { days }\end{array}$ & $\begin{array}{c}\text { Preop } \\
\text { FEV } 1 / \text { FVC } \\
\text { L }\end{array}$ & $\begin{array}{c}\text { Pred post } \\
\text { FEV } 1 / \text { FVC } \\
\text { L }\end{array}$ & $\begin{array}{l}F \mathrm{I}, \mathrm{O}_{2} \\
\mathrm{OLV}\end{array}$ & $\begin{array}{l}\text { OLV/GA } \\
\text { ratio } \\
\text { min }\end{array}$ & $\begin{array}{l}\text { TVoLV/ } \\
\text { TVDLV }\end{array}$ & $\begin{array}{l}\text { Fluid load } \\
\mathrm{mL} \cdot \mathrm{kg}^{-1} \cdot \mathrm{h}^{-1}\end{array}$ \\
\hline $59(\mathrm{M})$ & LPN & 33 & 7 & $3.4 / 4.5$ & $1.9 / 2.5$ & 0.6 & $65+45 / 270(0.4)$ & 0.93 & 14 \\
\hline $67(\mathrm{M})$ & LPN & 30 & 6 & $1.5 / 3.0$ & $1.1 / 1.2$ & 0.99 & $180 / 240(0.7)$ & 1.0 & 11 \\
\hline $66(\mathrm{M})$ & LPN & 31 & 8 & & & & & & \\
\hline $58(\mathrm{M})$ & $\begin{array}{l}\text { L completion } \\
\text { PN, chest wall } \\
\text { resection }\end{array}$ & 36 & 11 & $2.6 / 3.5$ & $2.6 / 3.5$ & 0.6 & $35 / 300(0.1)$ & 1.0 & 12 \\
\hline $76(F)$ & LPN & 32 & 7 & $1.4 / 2.2$ & $0.8 / 1.2$ & 0.6 & $75 / 233(0.3)$ & 0.7 & 8 \\
\hline $66(\mathrm{M})$ & LPN & 31 & 8 & $1.8 / 2.5$ & $1.2 / 2.6$ & 0.6 & $60 / 200(0.3)$ & 0.6 & 25 \\
\hline $50(\mathrm{~F})$ & RPN & 33 & $5 \mathrm{NS}$ & $2.1 / 2.9$ & $1.2 / 1.6$ & 0.99 & $105 / 170(0.5)$ & 1.2 & 14 \\
\hline $45(\mathrm{M})^{*}$ & RPN & 35 & $63 \mathrm{~S}$ & $3.0 / 3.6$ & $1.4 / 1.7$ & 0.99 & $240 / 360(0.7)$ & 1.0 & 11 \\
\hline $56(\mathrm{M})^{*}$ & LPN & 34 & 7 & $2.0 / 3.0$ & $1.1 / 1.6$ & 0.7 & $110 / 270(0.4)$ & 1.0 & 8 \\
\hline $\begin{array}{l}59.7 \\
(3.4)\end{array}$ & & $\begin{array}{c}33 \\
(0.7)\end{array}$ & $\begin{array}{l}14.4 \\
(6.96)\end{array}$ & $\begin{array}{c}2.3 / 3.2 \\
(0.3 / 0.3)\end{array}$ & & $\begin{array}{c}0.76 \\
(0.07)\end{array}$ & $\begin{array}{l}114 / 255 \\
(24 / 21)\end{array}$ & $\begin{array}{l}0.93 \\
(0.067)\end{array}$ & $\begin{array}{l}13 \\
(2.1)\end{array}$ \\
\hline $72(\mathrm{M})$ & RUL, RML & 35 & 10 & $1.8 / 2.9$ & $1.3 / 2.2$ & 0.8 & $75+22 / 240(0.4)$ & 1.0 & 11 \\
\hline $77(\mathrm{M})$ & Sleeve RUL & 36 & 7 & $2.6 / 4.0$ & $2.2 / 3.4$ & 0.5 & $106 / 146(0.7)$ & 0.8 & 15 \\
\hline $61(\mathrm{M})$ & Sleeve LLL & 26 & 7 & $2.0 / 2.9$ & $1.5 / 2.1$ & 0.6 & $90 / 150(0.6)$ & 1.2 & 18 \\
\hline $68(\mathrm{M})$ & RML, RLL & 29 & 7 & $2.6 / 4.1$ & $1.6 / 2.5$ & 0.7 & $58 / 180(0.32)$ & 1.0 & 8 \\
\hline $69(\mathrm{~F})^{*}$ & RUL, RML & 30 & 17 & $1.8 / 3.2$ & $1.3 / 2.4$ & 0.5 & $58 / 128(0.5)$ & 1.2 & 13 \\
\hline $69(\mathrm{M})$ & RML, RLL & 26 & 7 & $2.5 / 4.6$ & $1.6 / 2.8$ & 0.6 & $105 / 210(0.5)$ & 1.1 & 19 \\
\hline $68(\mathrm{M})$ & RUL & 29 & 8 & $1.8 / 4.0$ & $1.4 / 3.4$ & 0.5 & $18+58 / 210(0.4)$ & 0.9 & 13 \\
\hline $48(\mathrm{M})$ & LUL & 35 & 5 & $3.5 / 5.7$ & $2.5 / 3.6$ & 0.5 & $50 / 150(0.3)$ & 1.0 & 15 \\
\hline 66.5 & & 31 & 8.5 & $2.3 / 3.9$ & & 0.59 & $80 / 177$ & 1.025 & 14.2 \\
\hline (J.1) & & & & $(0.2 / 0.5)$ & & $(0.040)$ & $(0 / 14)$ & $(0.049)$ & $(1.2)$ \\
\hline $31(\mathrm{M})$ & $\begin{array}{l}\text { Wedge basal } \\
\text { segment RLL }\end{array}$ & 3.1 & 4 & $3.9 / 4.6$ & & 0.5 & $30 / 90(0.3)$ & 0.9 & 9 \\
\hline $72(\mathrm{M})$ & Pleural biopsy & 30 & 3 & $2.1 / 2.8$ & & 0.8 & $30 / 85(0.4)$ & 1.2 & 9 \\
\hline $64(\mathrm{M})$ & $\begin{array}{l}\mathrm{L} \text { thoracotomy } \\
\text { open and close }\end{array}$ & 40 & 4 & $2.3 / 3.4$ & & 0.6 & $20 / 80(0.25)$ & 1.0 & 11 \\
\hline $29(\mathrm{M})$ & $\begin{array}{l}\text { Repeat L } \\
\text { metastatectomy }\end{array}$ & 42 & 5 & $4.4 / 5.2$ & & 0.6 & $30 / 120(0.25)$ & 1.1 & 14 \\
\hline $66(M)$ & $\begin{array}{l}\text { Open lung } \\
\text { biopsy, } \\
\text { pleural biopsy, } \\
\text { pleurodesis }\end{array}$ & 36 & 5 & $2.8 / 4.0$ & & 0.5 & $25 / 100(0.25)$ & 0.6 & 14 \\
\hline $40(\mathrm{M})$ & $\begin{array}{l}\text { Lingular } \\
\text { resection }\end{array}$ & 34 & 7 & $2.2 / 3.2$ & $1.9 / 2.8$ & 0.6 & $15+35 / 150(0.3)$ & 0.8 & 6 \\
\hline $54(\mathrm{~F})$ & $\begin{array}{l}\text { Resection of } \\
\text { nodule, apical } \\
\text { segment RLL }\end{array}$ & 38 & 5 & $2.3 / 3.6$ & & 0.4 & $15 / 85(0.18)$ & 1.2 & 11 \\
\hline $48(\mathrm{~F})$ & $\begin{array}{l}\text { Resection of } \\
\text { three nodules: } \\
\text { two RUL, one } \\
\text { RLL }\end{array}$ & 40 & 6 & $1.8 / 2.2$ & & 0.6 & $30 / 130(0.4)$ & 1.0 & 6 \\
\hline $\begin{array}{l}5.1 \\
(5.7)\end{array}$ & & $\begin{array}{c}37 \\
(1.6)\end{array}$ & $\begin{array}{c}4.8 \\
(0.5)\end{array}$ & $\begin{array}{c}2.7 / 3.6 \\
(0.3 / 0.3)\end{array}$ & & $\begin{array}{c}0.575 \\
(0.042)\end{array}$ & $\begin{array}{l}29 / 105 \\
(4 / 9)\end{array}$ & $\begin{array}{c}0.975 \\
(0.073)\end{array}$ & $\begin{array}{l}10 \\
(1.1)\end{array}$ \\
\hline
\end{tabular}

*: Three patients developing acute respiratory distress syndrome following right pneumonectomy/or lobectomy. Preop: preoperative; post: postoperative; pred: predicted; FEV1: forced expiratory volume in one second; FVC: forced vital capacity; $F_{1}, \mathrm{O}_{2}$ : inspiratory oxygen fraction; M: male; F: female; L: left; R: right; PN: pneumonectomy; UL: upper lobe; ML: middle lobe; LL: lower lobe; OLV/GA: one lung ventilation/general anaesthetic; TVOLV/TVDLV: tidal volume ratio during collapse of one lung and ventilation of both lungs. S: survivor; NS: nonsurvivor. 
load, although the overall balances $24 \mathrm{~h}$ after the procedure were not significantly different. Three patients developed ARDS and, excluding these, postoperative stay was significantly shorter for patients undergoing lesser procedures as might be anticipated.

\section{Evidence of oxidative damage}

Baseline plasma protein thiol values $(4.5 \pm 0.8,4.7 \pm 0.4$ and $4.5 \pm 0.4 \mathrm{nmol} \cdot \mathrm{mg}^{-1}$ protein for pneumonectomy, lobectomy and biopsy or wedge resection, respectively) were significantly lower than those previously published for normal controls $\left(6.6 \pm 0.5 \mathrm{nmol} \cdot \mathrm{mg}^{-1}\right.$ protein) [17], but were comparable to those previously published for ventilated patients $\left(5.0 \pm 0.3 \mathrm{nmol} \cdot \mathrm{mg}^{-1}\right.$ protein) [17]. In the immediate postoperative period, plasma thiols fell significantly $(\mathrm{p}<0.05)$ from baseline $(-17.9 \pm 7.0 \%$ for pneumonectomy, $-24.3 \pm 5.5 \%$ for two-lobe lobectomy and $-10.2 \pm 2.2 \%$ for one-lobe lobectomy) (fig. 1), showing some recovery by the first postoperative day. By contrast, patients undergoing biopsy or wedge resection showed no significant change (fig. 1). Baseline plasma protein carbonyl values for each group $\left(1.4 \pm 0.1,1.4 \pm 0.1\right.$ and $1.3 \pm 0.1 \mathrm{nmol} \cdot \mathrm{mg}^{-1}$ protein for pneumonectomy, lobectomy and biopsy or wedge resection, respectively) were significantly higher than those published previously for normal healthy con-
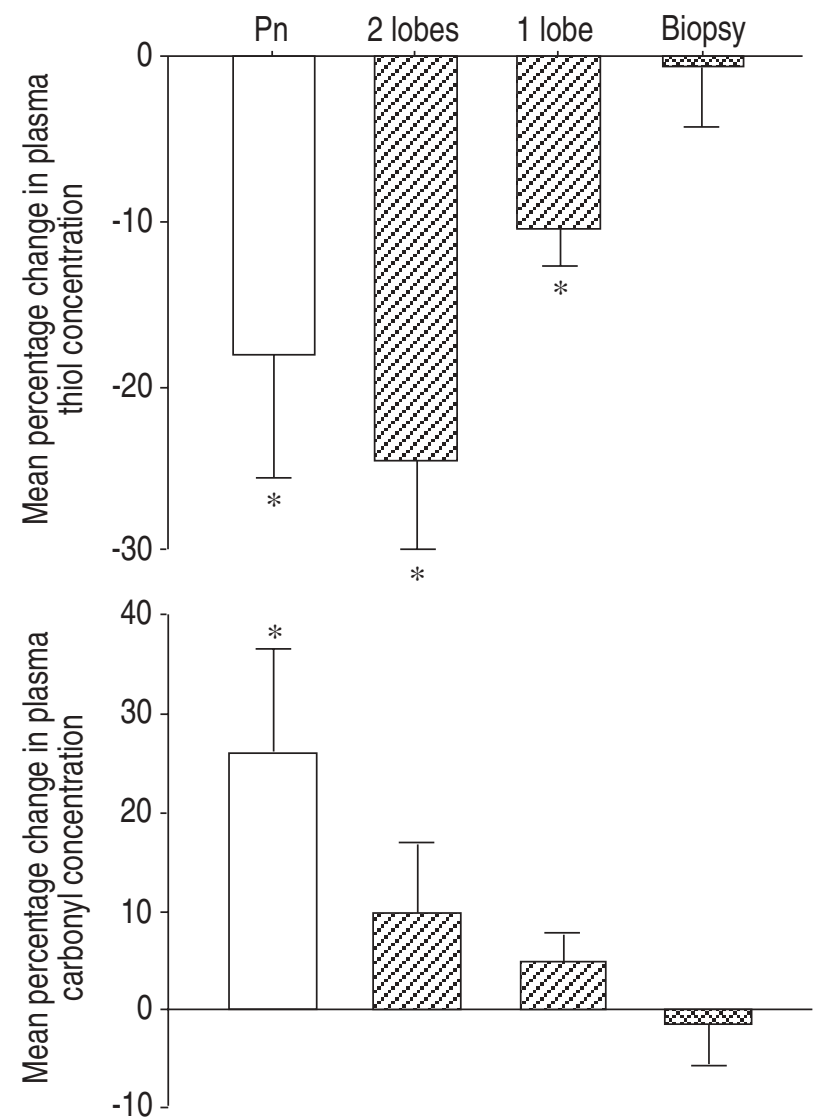

Fig. 1. - Perioperative change in plasma protein thiols and carbonyl concentrations for patients undergoing pneumonectomy $(\mathrm{Pn})(\mathrm{n}=8)$, lobectomy (one lobe $n=4$, two lobes $n=4$ ) and biopsy/wedge resection $(n=8)$. Values shown as mean \pm SEM percentage change between time point (TP) 1 (preoperation, postanaesthesia) and TP2 (in recovery or intensive care). $*: \mathrm{p}<0.05$. trols $\left(1.0 \pm 0.1 \mathrm{nmol} \cdot \mathrm{mg}^{-1}\right.$ protein, $\left.\mathrm{n}=6\right)$ [17], but were in a similar range to those published in ventilated intensive care unit (ICU) patients $\left(1.2 \pm 0.1 \mathrm{nmol} \cdot \mathrm{mg}^{-1}\right)$ [17]. Postoperatively, carbonyls rose significantly from baseline (26.2 \pm $10.5 \%$ for pneumonectomy, $9.8 \pm 7.0 \%$ for two-lobe lobectomy and $5.0 \pm 2.7 \%$ for one-lobe lobectomy) (fig. 1) and achieved a comparable absolute level to that described previously in ventilated patients with established ARDS [17]. Patients undergoing biopsy or wedge resection showed no significant changes (fig. 1). Patients undergoing abdominal surgery showed no significant differences in plasma thiol levels preoperatively $\left(5.2 \pm 0.3 \mathrm{nmol} \cdot \mathrm{mg}^{-1}\right.$ protein) versus postoperatively $\left(5.3 \pm 0.3 \mathrm{nmol} \cdot \mathrm{mg}^{-1}\right.$ protein, $\mathrm{p}<0.05)$, or for plasma carbonyl levels preoperatively $(2.2 \pm$ $0.1 \mathrm{nmol} \cdot \mathrm{mg}^{-1}$ protein) versus postoperatively $(2.2 \pm 0.2$ $\mathrm{nmol} \cdot \mathrm{mg}^{-1}$ protein, $\left.\mathrm{p}<0.05\right)$.
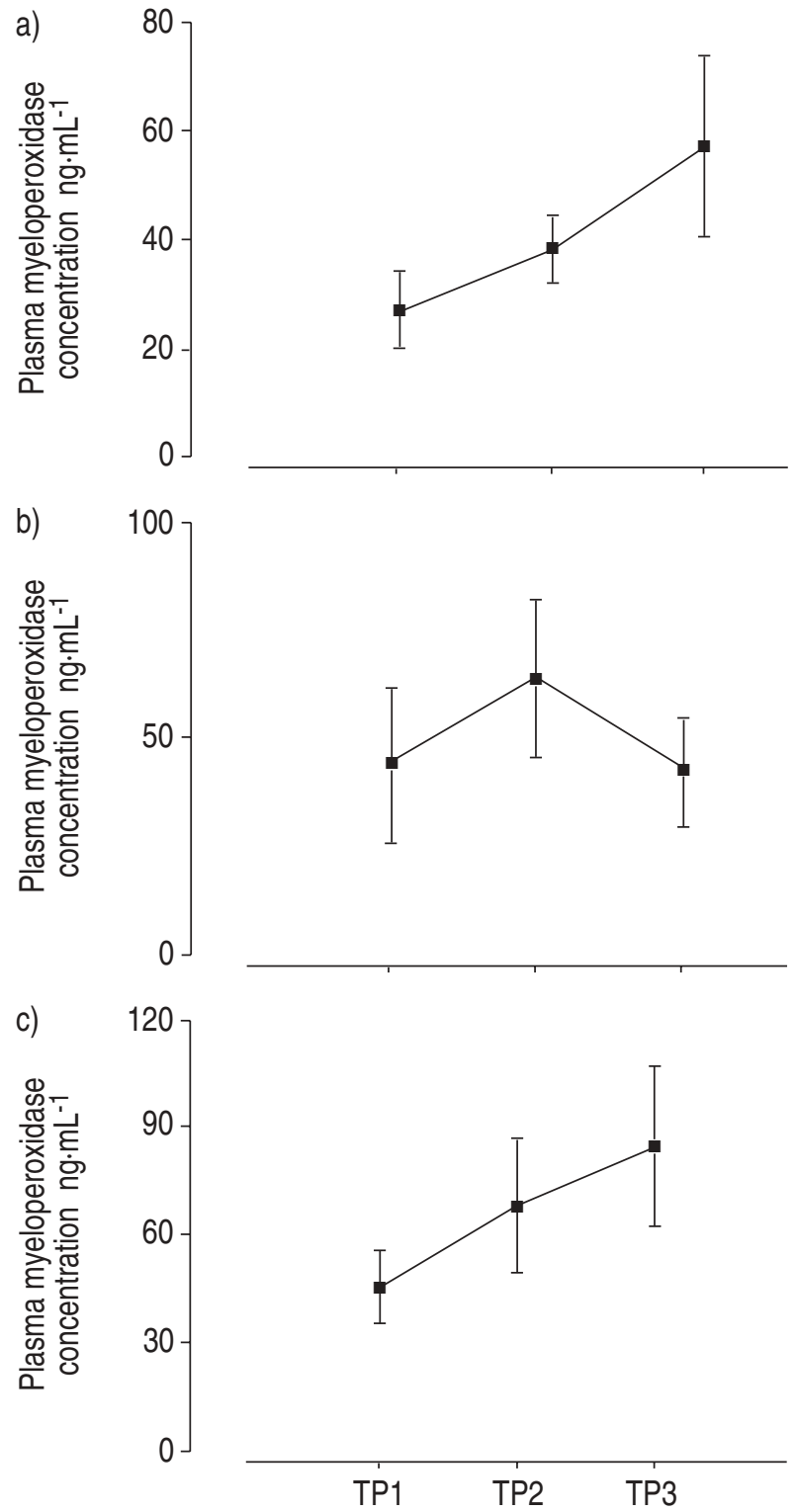

Fig. 2. - Perioperative change in plasma myeloperoxidase concentration for groups of patients undergoing: a) pneumonectomy; b) lobectomy; and c) biopsy or wedge resection ( $\mathrm{n}=18$ total) at time point (TP) 1 (preoperation, postanaesthesia); TP2 (in recovery or intensive care); and TP3 (24 h postoperatively). Results shown as mean \pm SEM. 


\section{MPO levels}

Baseline plasma MPO levels for all patients $(38.3 \pm 6.4$ $\mathrm{ng} \cdot \mathrm{mL}^{-1}, \mathrm{n}=18$ ) (fig. 2 ) were (35.2\%) higher than those in normal controls $\left(28.3 \pm 6.2 \mathrm{ng} \cdot \mathrm{mL}^{-1}, \mathrm{p}<0.05, \mathrm{n}=10\right)$ and were in agreement with previously published results for patients undergoing lung resection [4]. Plasma MPO rose perioperatively in all groups $(41.6 \%$ for pneumonectomy, $45.8 \%$ for lobectomy and $49.3 \%$ for biopsy or wedge resection) following correction for dilutional effects and remained increased for pneumonectomy $(111.3 \%)$ and biopsy or wedge resection patients $(86.7 \%)$ on the first postoperative day.

\section{Measurement of lung volumes and diffusing capacity}

TL,CO fell perioperatively for all patients except those undergoing wedge resection or biopsy (fig. 3). As expected, FRC also decreased perioperatively in all those undergoing pneumonectomy and lobectomy. In the former group, the proportional decrease in lung volume appeared to show a consistent correlation with the preoperative clinical and bronchoscopic assessment of ventilation distribution. There was a significant reduction in $\mathrm{KCO}$ for patients undergoing lobectomy $(\mathrm{p}<0.05)$, with the most marked fall occurring in the only patient who developed ARDS following resection of the right upper and right middle lobes (reduction of $75.8 \%$ from preoperative value). KCO was unaffected in patients undergoing wedge resection or biopsy. There was no change in KCO for patients undergoing pneumonectomy for the group as a whole. However, closer analysis of the individual data suggested that patients undergoing uncomplicated left-sided resection, with a normal split ventilation distribution preoperatively, displayed a significant increase in KCO perioperatively. The further study of matched cases would be necessary for statistical validation of this observation. The mean of the data for this group was skewed by a patient who underwent right-sided resection and developed ARDS on the second postoperative day, and was the only pneumonectomy patient in whom $K \mathrm{CO}$ decreased significantly perioperatively (reduction of $38.4 \%$ from preoperative values).

\section{Discussion}

The results of this study suggest that patients undergoing pulmonary resection are under oxidative stress, shown by a perioperative fall and rise, respectively, in plasma
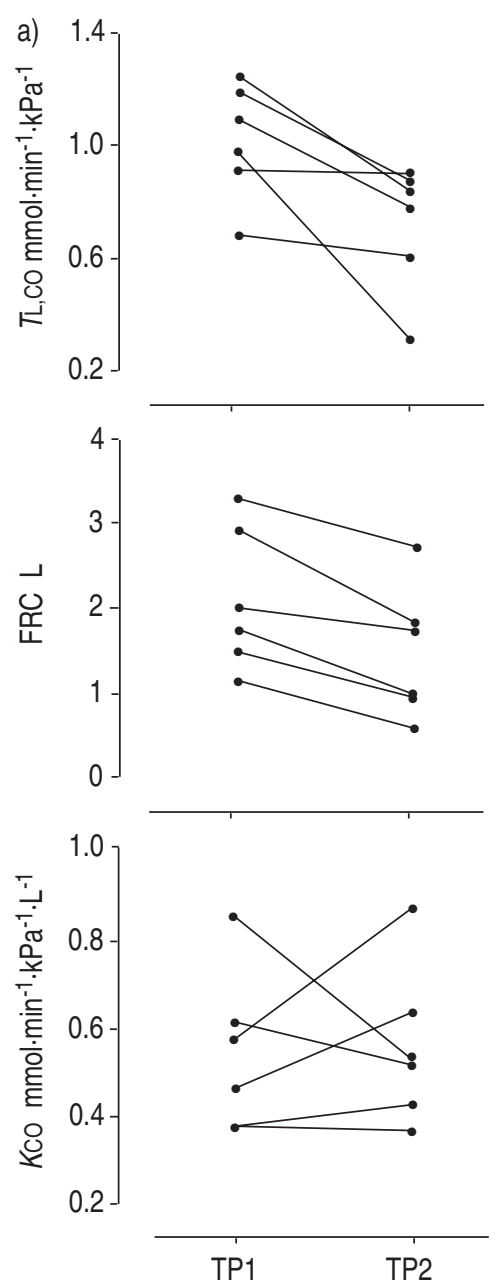
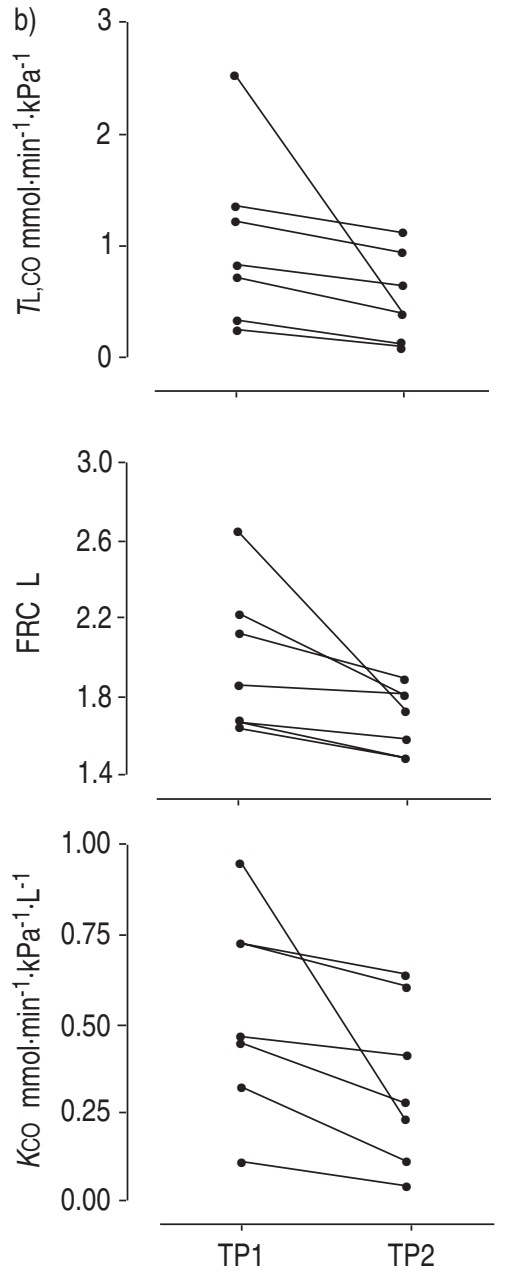


Fig. 3. - Perioperative change in diffusing capacity (TL,CO), functional residual capacity (FRC) and carbon monoxide transfer coefficient (KCO) in patients undergoing: a) pneumonectomy $(n=6)$; b) lobectomy $(n=7)$; and c) biopsy or wedge resection $(n=8)$ at time point $(T P) 1($ preoperation, postanaesthesia) and TP2 (in recovery or intensive care). 
protein thiol and carbonyl levels. These changes were not apparent in those only requiring biopsy or wedge resection or undergoing abdominal surgical procedures. KCO also fell in patients undergoing lobectomy, but not in those undergoing other lung resection, suggesting that significant functional damage to the lung occurred in the perioperative period.

Increasing awareness of the ubiquitous existence of ROS has led to the recognition of their role as significant contributory factors in many disease processes [21, 22]. Previous observations also support a role for ROS derived from neutrophil-dependent or independent sources in the initiation of the inflammatory processes that predispose to the development of ALI and ARDS [23].

Oxidative modification of biological molecules is known to impair their function. Common modifications indicative of the action of ROS include the formation of proteinassociated carbonyls [24] and the oxidation of protein thiol groups $[25,26]$. Indeed, thiol oxidation occurs in the fluid lining of the lungs of patients with ARDS [26]. Differences in the baseline levels of both indices in these patients compared with healthy controls may be accounted for in part by age-related factors, mechanical ventilation with high inspired oxygen concentrations and the underlying disease processes afflicting the study population, including previous treatment regimes and the effects of chronic smoke inhalation. An inverse relationship (at the three time points) between loss of plasma protein thiols and carbonyl formation was seen in the pneumonectomy and lobectomy patient groups (data not shown), but the formation of markers of oxidative damage was much less pronounced in the biopsy or wedge resection and abdominal surgery groups.

Although the precise role of the neutrophil in the causation of ARDS has been widely debated, neutrophil recruitment and activation within the lungs of patients with ALI or ARDS clearly act as a potential source of ROS [27]. In the current study, plasma MPO levels were elevated at baseline in all lung resection patients, as noted previously [4], and rose postoperatively, although not significantly. This might suggest a degree of neutrophil activation insufficient to mediate the oxidative damage detected at TP2, or that neutrophil activation had not yet developed fully. Thus, in previous studies of I-R-mediated myocardial injury, tissue neutrophil accumulation was not obvious until $24 \mathrm{~h}$ after the initial insult [28]. Finally, in ALI and ARDS, it is recognized that neutrophils are sequestered in the lungs. Plasma MPO levels may therefore not reflect locali-zed neutrophil activation in lung tissue and capillary beds.

In clinical practice much attention has focused on the ability of preoperative respiratory function to predict the high-risk candidate for surgical resection and to minimize avoidable postoperative morbidity and mortality. Therefore, in order to assess the effects of one-lung ventilation and operative procedure on gaseous exchange, the rebreathing method was utilized. The values measured were in agreement with those obtained in anaesthetized patients undergoing coronary artery bypass surgery [29]. Mean KCO fell in patients undergoing pneumonectomy and more markedly in all those undergoing lobectomy, but was not significantly different perioperatively in the biopsy or wedge resection group. Clearly, a fall in KCO not only reflects changes in membrane diffusing capacity, but cor- rects for a loss of accessible lung and pulmonary capillary blood volume consequent upon resection. Thus, measurements of $K \mathrm{CO}$ are an indication of the functional capacity of accessible alveoli preoperatively and postoperatively. I$\mathrm{R}$-mediated injury is expected to occur following lobectomy, in which the residual (i.e. unresected) ipsilateral lung is rendered (often repeatedly) ischaemic whilst resection of the lobe occurs. Thus, after lobectomy, KCO was expected to rise if no lung injury occurred (the same blood volume perfusing a smaller lung volume), but it consistently fell, implying that lung injury was measurable in the remaining accessible alveolar units. The results following pneumonectomy are more difficult to explain, but in these circumstances the resected lung is not subjected to repeated collapse and re-expansion. Thus, any fall in $K \mathrm{CO}$ is as likely to be attributable to hyperperfusion (i.e. hydrostatic) injury of the remaining (i.e. contralateral) lung as to IR-mediated injury per se. Indeed, individual data for patients undergoing uncomplicated left-sided resection with a normal split ventilation distribution preoperatively, showed a significant increase in $K \mathrm{CO}$, implying increased perfusion of undamaged accessible lung. Unfortunately, the results for this group were skewed by a single patient who developed ARDS postoperatively and in whom a severe fall in KCO was identified perioperatively (clearly identifiable in fig. 3). Comparisons between changes in the indices of oxidative damage (mean values) and $\mathrm{KCO}$ in all patient groups revealed correlations $(\mathrm{r}=0.47$ for carbonyls versus $K \mathrm{CO}, \mathrm{r}=0.44$ for thiols versus $\mathrm{KCO}$ ) suggestive of a causal relationship between ROS formation and lung injury. No such relationship was apparent when MPO levels were compared with $K \mathrm{CO}(\mathrm{r}=0.11)$, suggesting that neutrophil activation may not be a major factor in the injury process, and no correlations were found between markers of oxidative damage and MPO levels, further strengthening this argument. ROS can be formed by a variety of mechanisms including neutrophil activation, I-R, and as a result of hyperoxia. The results do not clearly demonstrate a role for the neutrophil as a source of ROS in these patients, so I-R and hyperoxia would seem to be the most likely sources of these oxidants. The lobectomy patient group was expected to be subjected to a greater degree of I-R injury than the pneumonectomy group, although this assumption is difficult to evaluate. Both groups showed evidence of pronounced oxidative injury in plas$\mathrm{ma}$, associated with operative procedures. I-R is probably a feature of both processes, but it is not possible to interpret further its contribution to the injury observed. Direct measurement of oxidative damage in the lung would probably provide a greater insight into the mechanisms involved.

The preoperative serum albumin level was significantly lower for patients undergoing lobectomy than for those requiring biopsy or wedge resection $(31 \pm 1.4$ versus $37 \pm$ $1.6 \mathrm{mg} \cdot \mathrm{mL}^{-1}, \mathrm{p}<0.05$ ) (table 1 ). We have no explanation for this difference, which may have contributed to subclinical pulmonary oedema formation and the greater fall in $K C O$ seen in this group (see below) through an adverse influence on oncotic pressure. However, there was no relationship between serum albumin and changes in indices of gas exchange ( $\mathrm{KCO}, \mathrm{Pa}_{\mathrm{a}} \mathrm{O}_{2}$ or $\mathrm{F} \mathrm{I}_{2} \mathrm{O}_{2}$ ) perioperatively in individual patients.

In summary, this study demonstrates that oxidative damage and lung injury occur following pulmonary resection. Changes occur in markers of oxidative protein damage 
with associated effects on gas exchange, processes which appear to be related. The duration of one-lung ventilation was significantly shorter for patients undergoing minor procedures, a group in which the occurrence of postoperative lung injury is unusual. The role of the neutrophil in the injury is not obvious. Production of reactive oxygen species during ischaemia-reperfusion and, possibly, ventilatory support are implicated as further contributing factors to postpneumonectomy pulmonary oedema in such surgical patients.

Acknowledgements: The authors would like to thank N. Soni for supplying the control surgical blood samples.

\section{References}

1. Zeldin RA, Normandin D, Landwing D, et al. Postpneumonectomy pulmonary edema. J Thorac Cardiovasc Surg 1984; 43: 323-326.

2. Shapira OM, Shahain MD. Postpneumonectomy pulmonary edema. Ann Thorac Surg 1993; 56: 190-195.

3. Bernard GR, Artigas A, Brigham KL, et al. The American-European Consensus Conference on ARDS. Am J Respir Crit Care Med 1994; 149: 818-824.

4. Waller DA, Gebiteken C, Saunders NR, et al. Postpneumonectomy pulmonary edema. Ann Thorac Surg 1993; 55: $140-143$

5. Turnage WS, Lunn JJ. Postpneumonectomy pulmonary edema. A retrospective analysis of the associated variable. Chest 1993; 103: 1646-1650.

6. Mathru M, Blakeman BP, Dries DJ, et al. Permeability edema following lung resection. Chest 1990; 95: 12161218.

7. Hayes JP, Williams EA, Goldstraw P, et al. Lung injury in patients following thoracotomy. Thorax 1995; 50: 990991.

8. Mathru M, Blakeman BP. Don't drown the "down" lung. Chest 1990; 103: 1644-1645.

9. Van der Werf YD, van der Houwen HK, Heijemans PJ, et al. Post pneumonectomy pulmonary edema. A retrospective analysis of incidence and possible risk factors. Chest 1997; 111: 1278-1284.

10. Dartevelle P, Maccharini P. Carinal resection for bronchogenic carcinoma. Semin Thorac Cardiovasc Surg 1996; 8: 414-425.

11. McCord JM. Oxygen-derived radicals: a link between reperfusion injury and inflammation. Fedn Proc 1987; 46: 2402-2406.

12. Adkinson D, Hollwarth ME, Benoit JN, et al. Role of free radicals in ischemia-reperfusion injury to the liver. Acta Physiol Scand 1986; 126: 101-108.

13. Anderson BO, Moore EE, Moore FA, et al. Hypovolemic shock promotes neutrophil sequestration in lungs by a xanthine oxidase-related mechanism. J Appl Physiol
1991; 7: 1862-1865.

14. Terada LS, Dormish JJ, Shanley PF, et al. Circulating xanthine oxidase mediates lung neutrophil sequestration after intestinal ischemia-perfusion. Am J Physiol 1992; 263: L394-L401.

15. Cochrane CG, Spragg R, Revak SD. Pathogenesis of the adult respiratory distress syndrome: evidence of oxidant activity in bronchoalveolar lavage fluid. J Clin Invest 1983; 71: 751-761.

16. Merritt TA, Cochrane CG, Holcomb K, et al. Elastase and alpha-1-proteinase inhibitor activity in tracheal aspirates during adult respiratory distress syndrome. J Clin Invest 1983; 72: 656-666.

17. Quinlan GJ, Evans TW, Gutteridge JMC. Oxidative damage to plasma proteins in adult respiratory distress syndrome. Free Rad Res 1994; 20: 289-298.

18. Dean RT, Fu S, Stocker R, Davies MJ. Biochemistry and pathology of radical-mediated protein oxidation. Biochem J 1997; 324: 1-18.

19. Macnaughton PD, Morgan CJ, Denison D, et al. Measurement of carbon monoxide transfer and lung volume in ventilated patients. Eur Respir J 1993; 6: 231-236.

20. Macnaughton PD, Evans TW. Measurement of lung volume and DLCO in acute respiratory failure. Am J Respir Crit Care Med 1994; 150: 770-775.

21. Gutteridge JMC. Free radicals in disease processes: a complication of cause and consequence. Free Rad Res 1993; 19: 141-148.

22. Baldwin SR, Grum CM, Boxer LA, et al. Oxidant activity in expired breath of patients with adult respiratory distress syndrome. Lancet 1986; i: 11-13.

23. Richard C, Lemonnier F, Thibault M, et al. Vitamin E deficiency and lipoperoxidation during adult respiratory distress syndrome. Crit Care Med 1990; 18: 4-9.

24. Radi R, Bush K, Cosgrove T, et al. Reaction of xanthine oxidase-derived oxidants with lipid and protein in human plasma. Arch Biochem Biophys 1991; 286: 117-125.

25. Era S, Kuwata K, Imai H, et al. Age-related change in the redox state of human serum albumin. Biochim Biophys Acta 1995; 1247: 12-16.

26. Bunnell E, Pact ER. Oxidised glutathione is increased in the alveolar fluid of patients with the adult respiratory distress syndrome. Am Rev Respir Dis 1993; 148: 1174 1178.

27. Tate RM, Repine JE. Neutrophils and the adult respiratory distress syndrome. Am Rev Respir Dis 1983; 125: 552-559.

28. Ferrari R. Oxygen free radicals at the myocardial level: effect of ischaemia and reperfusion. In: Armstrong D, ed. Free Radicals in Diagnostic Medicine. New York, Plenum Press, 1994; pp. 99-111.

29. Macnaughton PD, Braude S, Hunter DN, et al. Changes in lung and pulmonary microvascular after cardiopulmonary bypass. Crit Care Med 1992; 20: 1289-1294. 